\title{
Peritoneal transforming growth factor beta-1 expression during laparoscopic surgery: a clinical trial
}

\author{
Walter J. A. Brokelman • Lena Holmdahl •
}

Maria Bergström · Peter Falk · Jean H. G. Klinkenbijl •

Michel M. P. J. Reijnen

Published online: 11 July 2007

(C) Springer Science+Business Media, LLC 2007

\section{Erratum to: Surg Endosc}

DOI 10.1007/s00464-006-9164-x

Authors' name - Jean H. G. Klinkenbijl and Michel M. P. J. Reijnen was published incorrect. The spelling is now corrected here.

Springer regrets the errors.

The online version of the original article can be found under doi:10.1007/s00464-006-9164-X

W. J. A. Brokelman $(\bowtie) \cdot$ J. H. G. Klinkenbijl ·

M. M. P. J. Reijnen

Department of Surgery, Alysis Zorggroep, Locatie Rijnstate

Wagnerlaan, 55 6815, AD Arnhem, The Netherlands

e-mail:w.brokelman@planet.nl

L. Holmdahl · M. Bergström · P. Falk

Department of Surgery, Sahlgrenska University Hospital/östra,

Göteborg University, Göteborg, Sweden 